\title{
Treatment non-compliance and government aided health schemes : a boon or a curse
}

\author{
Manjula M.V. ${ }^{1}$, Pawar YS. ${ }^{2 *}$ \\ DOI: https://doi.org/10.17511/ijmrr.2019.i02.02 \\ 1 Manjula M.V., Department of Radiation Oncologist, Karnataka Institute of Medical Sciences, Hubballi, Karnataka, India. \\ 2* Y.S. Pawar, Department of Radiation Oncologist, Karnataka Institute of Medical Sciences, Hubballi, Karnataka, India.
}

Purpose: In this study we tried to analyze the prevalence of non-adherence to radiation treatment, the factors behind the unplanned breaks and the evaluation of strategies to overcome such breaks. Materials and Methods: Between January 2017 to October 2017, 486 patients were registered for radical radiotherapy of which 91 patients with unplanned treatment break were identified. We analyzed the social, economic, educational, and therapeutic barriers that led to treatment interruptions. Results: 91 patients of 486 patients registered for radical radiotherapy with unplanned treatment break were identified. The age of such patients ranged from 30 to 85 years with a median age of 52.5 years. 61 were males and 30 were females. 39 patients were from urban areas and 52 belonged to rural area. Of these 91 patients 85 patients were receiving cashless treatment based on BPL cards and 6 were cash paying patients. 52 Patients had Head and neck, 23 had gynecological, 7 with breast and 4 patients had esophageal cancers. Majority of patients in our study had treatment breaks during the mid to end phase of a radical radiotherapy schedule with the onset of Grade II or III acute reactions. Conclusion: As majority of patients were supported by government schemes without any binding factor, some compelling factors like blocking the BPL cards to avail other benefits, or to impose some kind of penalties to avoid wastage of government efforts and resources.

Keywords: Non- Compliance, Radiotherapy, Overall treatment time, Government aided schemes

Corresponding Author

Y.S. Pawar, Department of Radiation Oncologist, Karnataka Institute of Medical Sciences, Hubballi, Karnataka, India.

Email: dryspawar@gmail.com
How to Cite this Article

To Browse
Manjula MV, Pawar YS. Treatment non-compliance and government aided health schemes : a boon or a curse. Int J Med Res Rev. 2019;7(2):61-64.

Available From

https://ijmrr.medresearch.in/index.php/ijmrr/article/ view/1037

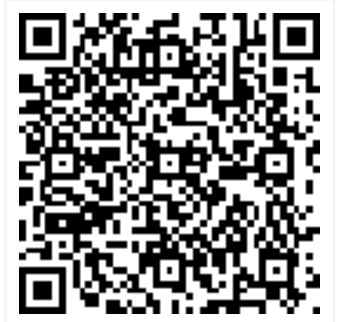

\begin{tabular}{|c|c|c|c|c|}
\hline & $\begin{array}{c}\text { Manuscript Received } \\
2019-01-20\end{array}$ & $\begin{array}{c}\text { Review Round } 1 \\
2019-01-30\end{array}$ & $\begin{array}{c}\text { Review Round } 2 \\
2019-02-07\end{array}$ & Review Round 3 \\
\hline & $\begin{array}{c}\text { Conflict of Interest } \\
\text { No }\end{array}$ & $\underset{\mathrm{Nil}}{\text { Funding }}$ & $\begin{array}{c}\text { Ethical Approval } \\
\text { Yes }\end{array}$ & $\begin{array}{c}\text { Plagiarism X-checker } \\
7 \%\end{array}$ \\
\hline OPEN & $\begin{array}{l}\text { (C) } 2019 \text { by } \\
\text { ACCESS }\end{array}$ & $\begin{array}{l}\text { S. Pawar and Publi } \\
\text { article licensed und } \\
\text { https://creativeco }\end{array}$ & $\begin{array}{l}\text { harth Health Resear } \\
\text { Commons Attributi } \\
\text { censes/by/4.0/ unp }\end{array}$ & $\begin{array}{l}\text { Nelfare Society. This is } \\
\text { ional License } \\
\text {.0]. }\end{array}$ \\
\hline
\end{tabular}




\section{Introduction}

Various studies have shown that Overall Total treatment time is an important factor, which influences the outcome of several malignancies $[1,2]$. Breaks in treatment have detrimental effect by allowing accelerated repopulation of malignant cells [3-5]. It has been estimated that the tumor stem cell doubling time for some cancers may be as short as 4 days during the time of accelerated repopulation [3].

Efforts have been made to overcome the accelerated tumor repopulation like reduction in over all treatment time, escalating the total dose delivered to the tumor, or by altered fractionation schedules like Hypo fractionation, Hyper fractionation, Concomitant boost or Concurrent use of chemotherapy. All these efforts are to achieve better overall outcome. According to World Health Organisation (WHO) [6] treatment Adherence is defined as "the extent to which a persons' behavior for taking medication, following a prescribed diet and or executing lifestyle changes, corresponds with agreed recommendation from a health care provider". Cancer treatment adherence is crucial to obtain optimal health outcomes as cure or improvement in quality of life. Non- adherence to prescribed cancer treatment has been shown to decreased survival, higher recurrences or treatment failure. Adherence is a multidimensional phenomenon and according to $\mathrm{WHO}$, is influenced by patient related factors, therapy related factors, social and economic related factors [6].

Unplanned treatment breaks during the course of radiotherapy in head and neck cancers is associated with worse loco-regional control rates, shorter overall and relapse free survival [1,7-9]. Prolongation of overall treatment time is associated with dismal outcome in cervical cancers, lung cancers, bladder cancers, esophageal, prostate, and breast cancers [10-13]. Planned interruptions usually occur during equipment maintenance and public holidays.

Treatment interruptions during a course of radiotherapy may be due to several factors like disease related factors such as clinical worsening or disease progression, treatment related factors such as side effects and toxicity of the treatment regimen, patient related factors such as lack of awareness, difficulty in logistics due to protracted course of treatment and low socio-economic conditions.
In this study we tried to analyze the prevalence of non-adherence to radiation treatment, the factors behind the unplanned breaks and the evaluation of strategies to overcome such breaks.

\section{Materials and Methods}

This is a prospective non-randomized study in which patients receiving radiation therapy in our hospital were screened for adherence to prescribed radiation regimen and patients with unplanned treatment breaks were recorded. All patients were scheduled treatment on 6MV Linac. Prior to start of treatment, all patients and their attendants were counseled regarding the importance of treatment, benefits and side effects. Contact address and numbers were collected by the Social worker of the department. Scheduled interruptions such as public holidays and weekends were excluded.

Variables such as age, gender, education, performance status, residential status, site of the disease, stage of the disease, treatment policy, total planned radiation dose, administration of concurrent chemotherapy, acute effects of treatment, number of days of treatment breaks, overall treatment time ,reasons for treatment interruption and patients who never turned back to treatment were recorded. Patients were assessed weekly for reactions and tumour response. Radiation Chart audit was scheduled every Saturday and appropriate measures were taken to keep track of noncompliant patients. We analyzed the social, economic, educational, and therapeutic barriers that led to treatment interruptions.

\section{Results}

Between January 2017 to October 2017, 486 patients were registered for radical radiotherapy of which 91 patients with unplanned treatment break were identified. The age of such patients ranged from 30 to 85 years with a median age of 52.5 years. Of the 91 patients with unplanned breaks, 61 were males and 30 were females. About 39 of patients were from urban areas and 52 were from neighboring rural areas. About 36 patients had completed only primary education and 50 were illiterate. Only 5 patients had completed higher primary school education. Majority of patients belonged to the lower socioeconomic class. Of these 91 patients 85 patients were receiving cashless treatment based on BPL cards and 6 were cash paying patients. 
52 patients had head and neck cancers. 23 patients had gynecological malignancy. Breast cancer patients were 7 and 4 had oesophageal cancers. Other malignancies like Myeloma, soft tissue sarcoma, and rectal cancers constituted rest of the total patients.

Among head and neck cancer patients, 29 patients had oral cavity cancers followed by or pharyngeal cancers which constituted 23 patients. Hypo pharyngeal and laryngeal cancer patients constituted 8 each of the total head and neck cancer patients. Among gynecological cancer patients, 17 patients had cervical cancers and 12 had endometrial cancer.

Our described barriers that hindered patients from completing the scheduled treatment were social barriers like lack of family and financial support. The therapeutic barriers included side effects of treatment andprotracted treatment duration. Educational barrier included poor understanding of the treatment and grave repercussions of discontinuing the treatment, also strong faith over nonscientific alternate treatments by local quacks. Emotional barrier were depression and anxiety because of the illness and fear of death with the deadly term "Cancer".

Out of 91 patients, 38\% of patients had socioeconomic barrier and $22 \%$ of patients discontinued due to treatment related factors. 3.5\% of patients hademotional barriers and $8.5 \%$ of patients had educational factors. $28 \%$ of patients had cluster of more than one factor. The number of days of treatment breaks ranged between 3 and 27 days.

\section{Discussion}

Successful outcome of radiation treatment depends on the total dose delivered with a balanced therapeutic gain. Non compliance to RT is a serious issue, since it not only results in incurability but also alters the natural progression of the disease. Subcurative doses of radiation results in the onset of accelerated repopulation of cancer cells which makes subsequent re-initiation of therapy challenging.

Prolongation of overall treatment time is associated with an adverse outcome, especially in tumors with rapid growth rates. It has been reported in head and neck cancers that 1 day treatment prolongation can result in $1.4 \%$ decrease in local control rate $[14,15]$.
Other malignancies where treatment prolongation can be detrimental include cervical cancers, lung cancers, esophageal cancers, medulloblastomas, and glioblas-tomas. Evidence shows that overall treatment time for squamous cell cancers of cervix should not exceed a period of 8 weeks.

In our study, a large majority of patients who had unplanned treatment breaks had head and neck and cervical cancers which have a high cell turnover. Majority of patients in our study had treatment breaks during the mid to end phase of a radical radio therapy schedule with the onset of Grade II or III acute reactions. This again is a matter of concern as accelerated repopulation of tumor cells occurs after 28 days of radiation treatment. The longer the duration of an unplanned treatment break, the more dismal is the outcome.

To overcome this issue, we conduct internal audits in the department to screen patients for adherence to treatment schedule and to the prescribed radiation treatment regimen. Educational barrier to adherence is due to a poor understanding of the nature of the disease, grave nature of the disease and the limited best treatment options. We tried to overcome this by arranging orientation programs for the patients at the time of reporting for treatment. A Department of Social worker maintained rapport with each patient to comfort them morally and inform the physician regarding patient's problems. The treating physicians and nursing staff responsibilities is to explain the treatment aspects, the expected side effects, profile of the treatment and the importance of adherence to the treatment schedule. Information material or a pamphlet containing information about the entire treatment by specific site were provided to the patient andor attenders.

Socioeconomic barriers can be overcome by extensive counseling of both patients and the attenders about the entire treatment process. A social welfare officer should discuss all the logistic issues with the patient and attenders at the beginning of treatment. To overcome the logistic issues, patients may be admitted in the ward or hospital dormitories and to undergo treatment asto ensure compliance to treatment. Therapeutic barrier poses a real challenge to the treating physician.

The importance of weight maintenance should be explained to the patients at the beginning of treatment, especially for patients with head and neck and GImalignancies. 
A nutritional and diet counseling should be given by a Departmental Nutritionist. Weekly assessment of weight, diet, and fluid intake should be done. A proper mouth care regimen should be designed for all head and neck cancer patients undergoing radiation.

The prevalence of depression and anxiety should be assessed by the treating physician or the radiation nurse and appropriate counseling should be done by adedicatedpsycho oncologist.

For patients who have unplanned treatment breaks early in the course of treatment an accelerated treatment schedulecan be planned by delivering twice a day treatment or by treating during weekends to compensate for the interruption.

For patients with interruptions in the late phase of treatment, appropriate radiobiology based calculations should be made and an increased total dose should be delivered to compensate for the radiation wasted due to accelerated repopulation.

Despite exhaustive counseling and moral and social support, patients were reluctant to complete the treatment. These patients had no compelling factor to complete the treatment. Financial constraint was not the true factor as majority of patients treatment was supported by government aided treatment schemes.

These government schemes dictate hospitals to deliver the treatment at the cost of zero expenditure. Majority of patients had false perception that they are being called for treatment as the hospital would be benefitted enormously by government and never felt the pain of any loss of any nature.

\section{Conclusion}

Identification of barriers that lead to non-adherence to treatment, and designing effective strategies to overcome such barriers and effective communication becomes imperative to ensure uninterrupted treatment and offer the best oncological outcome.

As majority of patients were supported by government schemes without any binding factor, some compelling factors like blocking the BPL cards to avail other benefits, or to impose some kind of penalties to avoid wastage of government efforts and resources. Strict protocols to maintain the

\section{Reference}

01. Rafal Suwinski, Anna Sowa, Tomaszrutkowski, et al. Time factor in postoperative radiotherapyA multivariate locoregional control analysis in 868 patients. Int J Radiat Oncol Biol Phys. 2003;56;399-412.

[Crossref]

02. González San Segundo C, Calvo Manuel FA, Santos Miranda JA. Delays and treatment interruptions- difficulties in administering radiotherapy in an ideal time-period. Clin Transl Oncol. 2005 Mar;7(2)47-54.

[Crossref]

03. Withers HR, Taylor JM, Maciejewski B. The hazard of accelerated tumor clonogen repopulation during radiotherapy. Acta Oncol. 1988;27(2)131-46.

[Crossref]

04. Tarnawski R, Fowler J, Skladowski K, et al. How fast is repopulation of tumor cells during the treatment gap?. Int J Radiat Oncol Biol Phys. 2002 Sep 1;54(1)229-36.

[Crossref]

05. Schmidt-Ullrich RK, Contessa JN, Dent P, et al. Molecular mechanisms of radiation-induced accelerated repopulation. Radiat Oncol Investig. 1999;7(6)321-30.

[Crossref]

06. Dale RG, Hendry JH, Jones $B$, et al. Practical methods for compensating for missed treatment days in radiotherapy, with particular reference to head and neck schedules. Clin Oncol (R Coll Radiol). 2002 Oct; 14(5)382-93.

[Crossref]

07. Hendry JH, Bentzen SM, Dale RG, et al. A modelled comparison of the effects of using different ways to compensate for missed treatment days in radiotherapy. Clin Oncol ( $R$ Coll Radiol). 1996;8(5)297-307.

[Crossref]

08. Robertson AG, Robertson C, Perone C, Clarke K, Dewar J, Elia $\mathrm{MH}$, et al. Effect of gap length and position on results of treatment of cancer of the larynx in Scotland by radiotherapy- A linear quadratic analysis. Radiother Oncol. $1998 ; 48 ; 165-173$.

[Crossref] 
09. Robertson C, Robertson AG, Hendry JH, et al. Similar decreases in local tumor control are calculated for treatment protraction and for interruptions in the radiotherapy of carcinoma of the larynx in four centers. Int J Radiat Oncol Biol Phys. 1998 Jan 15;40(2)319-29.

[Crossref]

10. Groome PA, O'Sullivan B, Mackillop WJ, Jackson LD, Schulze K, Irish JC, et al. Compromised local control due to treatment interruptions and late treatment breaks in early glottic cancerPopulation - based outcomes study supporting need for intensified treatment schedules. Int J RadiatOncol Biol Phys. 2006;64;1002-1012.

[Crossref]

11. Videtic GM, Fung $K$, Tomiak AT, et al. Using treatment interruptions to palliate the toxicity from concurrent chemoradiation for limited small cell lung cancer decreases survival and disease control. Lung Cancer. 2001 AugSep;33(2-3)249-58.

[Crossref]

12. Chen $M$, Jiang $G L, F u ~ X L$, et al. The impact of overall treatment time on outcomes in radiation therapy for non-small cell lung cancer. Lung Cancer. 2000 Apr;28(1)11-9.

[Crossref]
13. Perez CA, Michalski J, Mansur D, et al. Impact of elapsed treatment time on outcome of externalbeam radiation therapy for localized carcinoma of the prostate. Cancer J. 2004 NovDec;10(6)349-56.

[Crossref]

14. Maciejewski B, Majewski S. Dose fractionation and tumour repopulation in radiotherapy for bladder cancer. Radiother Oncol. 1991 Jul;21(3)163-70.

[Crossref]

15. Hendry JH, Roberts SA, Slevin NJ, Keane TJ, Barton MB, Agren-Cronqvist $A$, et al. Influence of radiotherapy treatment time on control of laryngeal cancer- Comparisons between centres in Manchester, UKand Toronto, Canada. Radiother Oncol. 1994;31;14-22. [Crossref]

16. Roberts SA, Hendry JH, Brewster AE, et al. The influence of radiotherapy treatment time on the control of laryngeal cancer- a direct analysis of data from two British Institute of Radiology trials to calculate the lag period and the time factor. Br J Radiol. 1994 Aug;67(800)790-4.

DOI: $\quad 10.1259 / 0007-1285-67-800-790$ [Crossref] 